\title{
El derecho fundamental a la estabilidad laboral reforzada, alcance de la protección constitucional por vía de tutela en Colombia
}

The fundamental right to reinforced labor stability, scope of constitutional protection by way of protective action in Colombia

O direito fundamental à estabilidade no emprego reforçada, alcance da proteção constitucional por meio de tutela na Colômbia

\section{Beatriz Delgado Motoa ${ }^{1}$}

Recibido: 12 de septiembre de 2019

Aprobado: 15 de octubre de 2019

Publicado: 25 de noviembre de 2019

Cómo citar este artículo: Beatriz Delgado Motoa. El derecho fundamental a la estabilidad laboral reforzada, alcance de la protección constitucional por vía de tutela en Colombia.

DIXI 30, julio-diciembre 2019, 1-20. DOI: https://doi.org/10.16925/2357-5891.2019.02.06

Artículo de investigación. https://doi.org/10.16925/2357-5891.2019.02.06

1 Magíster de la Universidad Sergio Arboleda de Bogotá, especialista en Derecho Privado de la Universidad Pontificia Bolivariana de Medellín, especialista en Instituciones Jurídicas de la Universidad Nacional de Colombia, abogada de la Universidad Santiago de Cali. Juez Civil Municipal por 22 años.

Correo electrónico: bedelgadom@hotmail.com 


\section{Resumen}

Propósito: la estabilidad laboral pretende otorgar un carácter permanente a la relación de trabajo, en la que el trabajador pueda decidir voluntariamente si continua o no en el puesto de trabajo y que solo en casos excepcionales el empleador pueda resolver esa relación. En Colombia existe la estabilidad relativa; solo en casos especiales se presenta la estabilidad absoluta, en la que el derecho al trabajo es aún más fuerte, por lo cual en tales eventos cabe hablar de un derecho constitucional de carácter fundamental a la estabilidad laboral reforzada.

Metodología: el artículo se fundamenta en el estudio de sentencias constitucionales, orientado a mostrar cómo la Corte Constitucional, a través de su doctrina construida vía sentencias de tutela (sentencias tipo T), sentencias de constitucionalidad (sentencias tipo C) y sentencias de unificación (sentencias tipo SU), ha construido las reglas del derecho constitucional de carácter fundamental a la estabilidad laboral reforzada y el alcance de su protección por vía de tutela, a partir de la sentencia C- 470 de 1997, con ponencia del Dr. Alejandro Martínez Caballero.

Hallazgos y conclusiones: la Corte Constitucional ha considerado que existen algunos casos en los que el derecho a la estabilidad en el empleo, consagrado en el artículo 53 de la Constitución Política, merece mayor protección.

Palabras clave: acción de tutela, derechos fundamentales, estabilidad laboral, estabilidad laboral reforzada, Estado social de derecho.

\section{Abstract}

Purpose: Labor stability is intended to give a permanent character to the employment relationship, in which the worker can voluntarily decide whether to continue in the job; and only in exceptional cases, the employer can resolve the relationship. In Colombia, there is relative stability; only in special cases there is absolute stability, in which the right to work is even stronger, so that in such events we can speak of a fundamental constitutional right to reinforced labor stability.

Methodology: The article is based on the study of constitutional sentences, in order to show how the Constitutional Court has established the rules of the fundamental constitutional right to reinforced labor stability, and the scope of its protection through protective action sentences, starting with sentence C-470 of 1997, with a paper by Dr. Alejandro Martínez Caballero. The doctrine of the Constitutional Court is constructed through protective action sentences (type $T$ sentences), constitutionality sentences (type $\mathrm{C}$ sentences) and unification sentences (type SU sentences).

Findings and conclusions: The Constitutional Court has considered that there are some cases in which the right to labor stability, enshrined in Article 53 of the Political Constitution, deserves greater protection.

Keywords: Protective action, fundamental rights, labor stability, enhanced labor stability, social state under the rule of law.

\section{Resumo}

Propósito: a estabilidade no emprego pretende outorgar um caráter permanente à relação de trabalho, na qual o trabalhador possa decidir, de forma voluntária, se continua ou não no posto de trabalho e que somente em casos excepcionais o empregador possa resolver essa relação. Na Colômbia, existe a estabilidade relativa; somente em casos especiais é apresentada a estabilidade absoluta, na qual o direito ao trabalho é ainda mais forte; portanto, em tais eventos, cabe falar de um direito constitucional de caráter fundamental à estabilidade no emprego reforçada. 
Metodologia: este artigo se baseia no estudo de sentenças constitucionais, orientado a mostrar como a Corte Constitucional, por meio de sua doutrina construída via sentenças de tutela (sentencias tipo T), sentenças de constitucionalidade (sentenças tipo C) e sentenças de unificação (sentenças tipo SU), vem construindo as regras do direito constitucional de caráter fundamental à estabilidade no emprego reforçada e ao alcance de sua proteção mediante tutela, a partir da sentença C-470 de 1997, do juiz relator Dr. Alejandro Martínez Caballero.

Achados e conclusões: a Corte Constitucional tem considerado que existem alguns casos em que o direito à estabilidade no emprego, consagrado no artigo 53 da Constituição Política, merece maior proteção.

Palavras-chave: ação de tutela, direitos fundamentais, estabilidade no trabalho, estabilidade no emprego reforçada, Estado social de direito.

\section{INTRODUCCIÓN}

El artículo 1 de la Constitución erige al Estado social de derecho como principio medular de nuestra organización política. El concepto de Estado social de derecho nació en Europa en la segunda mitad del siglo xx como una forma de organización estatal encaminada a "realizar la justicia social y la dignidad humana mediante la sujeción de las autoridades públicas a los principios, derechos y deberes sociales de orden constitucional"1. En esa medida, el presupuesto central sobre el cual se construye este tipo de organización política es el de una íntima e inescindible interrelación entre las esferas del "Estado" y la "sociedad", la cual se visualiza ya no como un ente compuesto de sujetos libres e iguales en abstracto, según ocurría bajo la fórmula clásica del Estado liberal decimonónico, sino como un conglomerado de personas y grupos en condiciones de desigualdad real².

Así, el papel del Estado social de derecho consiste en "crear los supuestos sociales de la misma libertad para todos, esto es, de suprimir la desigualdad social"3; según lo ha señalado la Corte Constitucional, "con el término 'social' se señala que la acción del Estado debe dirigirse a garantizarle a los asociados condiciones de vida dignas. Es decir, con este concepto se resalta que la voluntad del Constituyente en torno al Estado no se reduce a exigir de este que no interfiera o recorte las

1 Corte Constitucional de Colombia. SENTENCIA C-1064 de 2001. (MP Manuel José Cepeda Espinosa y Jaime Córdoba Triviño; octubre 10 de 2001).

2 Corte Constitucional de Colombia. SENTENCIA C-566 de 1995. (MP Eduardo Cifuentes Muñoz; noviembre 30 de 1995).

3 Véase Ernst Wolfgang Böckenförde. ESTUDIOS SOBRE ESTADO DE DERECHO Y DEMOCRACIA. Editorial Trotta. (2000). Pág. 37. 
libertades de las personas, sino que también exige que el mismo se ponga en movimiento para contrarrestar las desigualdades sociales existentes y para ofrecerle a todos las oportunidades necesarias para desarrollar sus aptitudes y para superar los apremios materiales"4.

El principio del Estado social de derecho contrasta con el Estado de derecho liberal en cuanto a sus fines: el Estado social de derecho ya no se limita solamente a asegurar la vida, la propiedad y la libertad mediante la protección contra el fraude, el hurto, el incumplimiento contractual o los daños ocasionados por terceros, funciones típicas del Estado gendarme. Sus fines tienen mayor alcance e incluyen, entre otros: promover la prosperidad general; garantizar la efectividad de los principios, derechos y deberes consagrados en la Constitución; facilitar la participación de todos en las decisiones que los afectan y en la vida económica, política, administrativa y cultural de la Nación; y asegurar la vigencia de un orden justo (art. 2 de la CP). Para ello, el Estado cuenta con facultades amplias de intervención en la economía, las cuales han de estar orientadas a lograr los fines generales del Estado y los fines especiales de la intervención económica enunciados principalmente en el artículo 334 de la Constitución. Entre estos fines especiales se destacan el de "asegurar que todas las personas, en particular las de menores ingresos, tengan acceso efectivo a los bienes y servicios básicos" (art. 334 de la CP, inc. 2).

El alcance del principio de Estado social de derecho respecto a la relación entre las autoridades y la persona individualmente considerada es bastante amplio, y se ve reforzado por los principios fundamentales de la dignidad humana, el trabajo, la solidaridad (art. 1 de la CP) y la igualdad (art. 13 de la CP).

En cuanto a la dignidad humana, las autoridades públicas no pueden tratar al ser humano como una cosa o mercancía, ni ser indiferentes frente a situaciones que ponen en peligro el valor intrínseco de la vida humana, entendida esta no ya como el derecho a no ser físicamente eliminado, sino como el derecho a realizar las capacidades humanas y a llevar una existencia con sentido, en un ambiente libre de miedo frente a la carencia de lo materialmente necesario e indispensable para subsistir dignamente.

El principio fundamental del trabajo sobre el que igualmente se funda el Estado social de derecho (art. 1 de la CP) justifica, entre otras, la intervención del Estado en la economía, como ya se anotó, "para dar pleno empleo a los recursos humanos y asegurar que todas las personas, en particular las de menores ingresos, tengan acceso efectivo a los bienes y servicios básicos" (artículo 334 inciso 2 CP). De esta

\footnotetext{
4 Corte Constitucional de Colombia. SENTENCIA SU-747 de 1998. (MP Eduardo Cifuentes Muñoz; diciembre 2 de 1998).
} 
forma, el Estado Social, por medio de la política económica y social adoptada por las autoridades competentes, pasa a ser agente de estímulo a la creación de empleo en el mercado laboral, todo ello dentro del marco constitucional de protección especial al trabajo (artículos 25 y $53 \mathrm{CP}$ ).

La solidaridad, como tercer pilar del Estado social del derecho, es un principio fundamental del que se derivan múltiples derechos - por ejemplo, los de equidad y progresividad tributaria (artículo 363 CP) o a la seguridad social (artículo 48)—, o deberes, por ejemplo, a obrar con acciones humanitarias ante situaciones que pongan en peligro la vida o la salud de las personas, todos ellos aplicables tanto al Estado como a los particulares.

\section{Medidas tributarias}

El principio y derecho fundamental a la igualdad, en sus múltiples manifestaciones -incluyendo la igualdad de oportunidades, la igualdad real y efectiva, o las acciones afirmativas a favor de grupos discriminados o marginados y de personas que por su condición económica, física o mental se encuentren en circunstancia de debilidad manifiesta (artículo $13 \mathrm{CP}$ ) —, representa la garantía más tangible del Estado social de derecho para el individuo o para grupos de personas expuestos a sufrir un deterioro de sus condiciones de vida como sujetos de una sociedad democrática, donde todas las personas merecen la misma consideración y respeto en cuanto seres humanos. Es a partir precisamente del artículo 13, en concordancia con los artículos 1, 2, 11 y 85 de la Constitución, que la jurisprudencia constitucional ha reconocido desde un principio el derecho fundamental al mínimo vital, el cual adquiere especial relevancia en el contexto de la intervención del Estado en la economía, en virtud del artículo 334 superior.

Las medidas adoptadas por las autoridades en el marco de un Estado social de derecho han de consultar la realidad fáctica sobre la cual habrán de surtir efectos, con miras a materializar la finalidad primordial adscrita por esta fórmula política a las instituciones públicas: promover condiciones de vida dignas para la totalidad de la población. Ello es especialmente predicable de las leyes en materia económica y mucho más de las disposiciones tributarias, según lo ha precisado la Corte Constitucional en varias oportunidades.

Así, por ejemplo, en la Sentencia C-925 del 2000 se estableció que, en virtud de la existencia de un deber constitucional general de las personas consistente en "contribuir al financiamiento de los gastos e inversiones del Estado dentro de conceptos de justicia y equidad" (art. 95-9 CP), el legislador, al adoptar las normas tributarias en 
virtud de las cuales se hará efectivo dicho deber, tiene que partir del hecho de que "no todos los asociados pueden ni deben tributar exactamente igual, sino que a la ley corresponde medir y distribuir las cargas. Y ello, según las capacidades y de acuerdo con la posición y necesidades de los distintos sectores sociales, teniendo en cuenta también la magnitud de los beneficios que cada uno de ellos recibe del Estado y las responsabilidades que, según su actividad, deben asumir; es la propia ley la encargada de señalar la cobertura de las normas tributarias y de establecer la mayor o menor medida en que cada uno tribute". En esa medida, se estableció en la misma providencia que compete al legislador tributario "evaluar, junto con los objetivos del recaudo, la equidad de las obligaciones que impone, la progresividad de las contribuciones y las distintas situaciones en que pueden encontrarse los contribuyentes".

La Corte también ha precisado, en relación con las medidas tributarias adoptadas por el legislador, que los principios de eficiencia, equidad y progresividad que según el artículo 363 superior rigen el sistema tributario se derivan directamente de la configuración de Colombia como un Estado social de derecho, en el marco del cual la hacienda pública cumple un propósito claramente redistributivo, "que se busca a través del diseño de instrumentos y políticas que procuren una mejor redistribución de la renta global del país, y del logro de una mejora relativa en los segmentos más pobres de la sociedad, a través del incremento cualitativo y cuantitativo de los servicios públicos"5 (Corte Constitucional, Sentencia C-776 de 2003).

\section{Evolución conceptual}

La estabilidad laboral es el derecho que tiene toda persona a permanecer en el empleo y a obtener los correspondientes beneficios salariales y prestacionales, incluso contra la voluntad del patrono, si no existe una causa relevante que justifique el despido. Esta garantía pretende otorgar un carácter permanente a la relación de trabajo, donde el trabajador pueda decidir voluntariamente si continua o no en el puesto de trabajo, y que solo en casos excepcionales contemplados en la ley el empleador pueda disolver dicha relación.

Según el panorama laboral actual, y desde hace ya un tiempo, se ha dado cabida en el mundo laboral contemporáneo y en Colombia a la flexibilidad del trabajo, estabilidad relativa, que riñe con el principio de estabilidad absoluta. Los empresarios acusan a la crisis económica de su aparición, ajustando al trabajador en horarios flexibles y trabajos temporales, desplazando el contrato a término indeterminado.

5 Corte Constitucional de Colombia. SENTENCIA C-080 de 1996. (MP Fabio Morón Díaz; febrero 29 de 1996). 
Modelos de contratación que han dado cabida a la llamada tercerización laboral, por medio de cooperativas y precooperativas, con la anuencia del Gobierno y la omisión del legislador; tales modelos creyeron en la buena fe de los empresarios cuando argumentaron que solo reducirían las tasas de desempleo en el país modificando las condiciones contractuales actualmente rígidas por unas más flexibles.

El concepto de estabilidad deviene de la "cualidad de estable", que en la primera acepción del Diccionario de la lengua española alude a lo que "se mantiene sin peligro de cambiar, caer o desaparecer"6; y en el Diccionario enciclopédico de derecho usual, de Guillermo Cabanellas? ${ }^{7}$, encontramos que en el ámbito laboral la estabilidad consiste en el derecho de un trabajador a conservar su puesto de trabajo indefinidamente, de no incurrir en faltas previamente determinadas o de no acaecer especialísimas circunstancias; es un factor que se deriva de la característica de tracto sucesivo propio del contrato de trabajo.

Al respecto, Adalberto Carvajal Salcedo la define como "la garantía que debe tener el trabajador de no ser despedido, suspendido, removido, trasladado o desmejorado de su cargo y de su sitio de trabajo, sino por justas causas previamente definidas en las normas legales preestablecidas con procedimientos dentro de los cuales se garantiza al inculpado el pleno derecho a la defensa, sin llegar a la posición utópica de pensar que en una sociedad con contradicciones de clases puede obtenerse la estabilidad plena del trabajador"8.

Para el tratadista Guillermo Guerrero Figueroa, "este principio constituye una medida de seguridad económica para la empresa, y responde a la intención de crear una nueva forma de convivencia humana basada en la estabilidad del trabajador. El derecho del trabajo procura la estabilidad del trabajador, tanto en el presente como en el porvenir. Todo lo que se encamine hacia la conservación de la fuente de trabajo constituye un beneficio para las partes del contrato de trabajo y para la sociedad, ya que contribuye a aumentar el rendimiento"?.

Alberto Vásquez Vialard sostiene que: "El derecho a la continuidad tiene como objeto satisfacer la necesidad de seguridad por parte del trabajador, pero también puede supeditarse a la función social que el trabajador cumple como miembro de una

6 Véase Real Academia Española. DICCIONARIO DE LA LENGUA ESPAÑOLA. 23.a edición. RAE. (2014).

7 Véase Guillermo Cabanellas de Torres. DICCIONARIO ENCICLOPÉDICO DE DERECHO USUAL. Heliasta. (1979). Pág. 360.

8 Véase Adalberto Carvajal Salcedo. EdUCADORES FRENTE A LA LEY LABORAL. 3. ${ }^{a}$ edición. Rodríguez Quito Editores. (1985). Pág. 86.

9 Véase Guillermo Guerrero Figueroa. COMPENDIO DEL DERECHO LABORAL. Leyer. (1998). Pág. 215. 
comunidad productora de bienes y servicios a favor de la comunidad global. Por lo tanto, pueden darse situaciones en que, a causa del bien común, puede ese derecho diluirse con la percepción de una indemnización. Tampoco el trabajador puede tener derecho a permanecer en el empleo contra la voluntad expresa del empleador, salvo en los casos en que se admita la estabilidad absoluta"10.

Jairo Villegas Arbeláez argumenta que:

[...] es una manifestación del principio de seguridad, pues como el trabajo, además de ser medio de sustento vital, es una manifestación del libre desarrollo de la personalidad. Se hace entonces necesario que exista una estabilidad básica en dicho empleo, que no significa que el trabajador sea inamovible en términos absolutos, porque siempre se tendrán en cuenta las justas causas para dar por terminado el empleo. Pero sí es conveniente que se siente como principio laboral la estabilidad, como garantía del trabajador a permanecer en su actividad de provecho tanto propio como social. Toda norma que tienda a vulnerar este principio es, en definitiva, no solo un retroceso que supone olvidar logros por los cuales la humanidad ha luchado denodadamente, sino que contraría los fines de la persona en sociedad. La estabilidad en el empleo tiene un doble fin, derivado, como ya se ha enunciado, del principio de seguridad. Por un lado, garantiza un medio para el sustento vital, y por otro, garantiza la trascendencia del individuo en la sociedad por medio del trabajo, en atención a la sociabilidad del hombre"1.

No hay duda, y en eso estamos de acuerdo, de que la estabilidad laboral consiste en el derecho que un trabajador tiene a conservar su puesto de trabajo, de no incurrir en faltas previamente determinadas o de no acaecer en circunstancias extrañas, lo que significa que el mismo derecho no es absoluto, sino relativo, sujeto a causa legal. Sin embargo, al tratarse de un sistema de estabilidad, se requiere obviamente de la existencia de una causa legal y justa para poder proceder al término de la relación laboral. Sin embargo, su característica esencial es que si el despido del trabajador es nulo por no concurrir una causa legal y justa, el empleador debe reintegrar al

10 Véase Antonio Vasquez Vialard. DERECHO DEL TRABAJO Y DE LA SEGURIDAD SOCIAL. Astrea. (1999). Pág. 216.

11 Véase Jairo Villegas Arbeláez. DERECHo ADMINISTRATIVo LABORAL. TOMO I. Editorial Legis. (1993). Pág.59. 
trabajador a la empresa y a su puesto de trabajo, pues debe volverse a la situación anterior al despido, careciendo el empleador de una opción distinta al reintegro.

En vigencia de la Constitución Política de 1886, la legislación laboral vigente consagraba normas de protección a la maternidad, artículos 236 al 241 Código Sustantivo del Trabajo-CST, y para los directivos, artículo 405 CST.

El artículo 236 cst, Subrogado. L. 50/90, art. 34 establece que toda trabajadora en estado de embarazo tiene derecho a una licencia de doce (12) semanas en la época del parto, remunerada con el salario que devengue al entrar a disfrutar el descanso. Si se tratara de un salario que no sea fijo, como en el caso de trabajo a destajo o por tarea, se toma en cuenta el salario promedio devengado por la trabajadora en el último de los servicios o en todo el tiempo si fuere menor.

El ordinal 3 de artículo 239 cst, modificado por el artículo 35 de la Ley 50 de 1990, consagra que ninguna mujer pueda ser despedida por motivos de embarazo o lactancia. Si la trabajadora en estado de gravidez o dentro de los tres meses posteriores al parto fue despedida sin previa autorización del inspector del trabajo, o alcalde en los lugares donde no exista o no se cuente con inspector del trabajo, y presume que el despido se ha efectuado por motivo de embarazo o lactancia, tiene derecho al pago de una indemnización equivalente a los salarios de sesenta (60) días fuera de las indemnizaciones y prestaciones a que hubiera lugar de acuerdo con el contrato de trabajo y, además, al pago de doce (12) semanas de descanso remunerado si no lo ha tomado.

El artículo 405 del Código Sustantivo del Trabajo ${ }^{12}$ desarrolla el concepto de fuero sindical como una garantía de la que gozan algunos trabajadores de no ser despedidos, ni desmejorados en sus condiciones de trabajo, ni trasladados a otros establecimientos de la misma empresa o a un municipio distinto, sin justa causa, previamente calificada por el juez del trabajo.

12 Código Sustantivo del Trabajo. ARTículo 405. DEFINICIÓN. Modificado por el art. 1, Decreto Legislativo 204 de 1957. El nuevo texto es el siguiente: Se denomina "fuero sindical" a la garantía de que gozan algunos trabajadores de no ser despedidos, ni desmejorados en sus condiciones de trabajo, ni trasladados a otros establecimientos de la misma empresa o a un municipio distinto, sin justa causa, previamente calificada por el juez del trabajo. Texto modificado del Decreto Ley 616 de 1954: ARTículo 405. FUERO SINDICAL. Se denomina "fuero sindical" a la garantía de que gozan algunos trabajadores de no ser despedidos, ni desmejorados en sus condiciones de trabajo, ni trasladados a otros establecimientos de la misma empresa o a un Municipio distinto sin justa causa, previamente calificada por el Ministerio del Trabajo. Texto original del Código Sustantivo del Trabajo: ARTículo 405. DEFINICIÓN. Se denomina "fuero sindical" a la garantía de que gozan algunos trabajadores de no ser despedidos, trasladados ni desmejorados en sus condiciones de trabajo, sin justa causa, previamente calificada por el juez del trabajo. 
Para la Corte, "los trabajadores que gozan de fuero sindical, la protección se otorga en razón a su pertenencia a un sindicato y como protección a sus derechos de asociación y sindicalización. Por tanto, cualquier decisión del patrono que modifique las condiciones de su contrato de trabajo, debe ser autorizada por el juez. El reintegro y el pago de los salarios dejados de percibir son las sanciones que se imponen al empleador que ha despedido o desmejorado las condiciones del trabajador amparado con fuero"13.

La legislación laboral ${ }^{14}$ vigente antes de 1991 aseguraba la permanencia en el empleo para los directivos sindicales, quienes solo podían ser retirados de su cargo mediante orden judicial, pero no la de la mujer trabajadora que se encontrara en estado de gravidez, por cuanto la misma ley autorizaba al empleador a despedirla de manera unilateral, sin previa autorización de autoridad competente, solo con el pago de una indemnización; es decir, no garantizaba su permanencia en el empleo, ni siquiera por su especial condición; por el contrario, bastaba que el empleador asumiera el pago de la indemnización para que se materializara el despido de una mujer en estas condiciones.

El legislador y de los funcionarios de la época desconocían los múltiples convenios internacionales de derechos humanos, que ordenan un especial cuidado a la mujer y a la maternidad en este campo. Por citar algunos ejemplos, se destaca que la Declaración Universal de Derechos Humanos, en el artículo 25, señala que "la maternidad y la infancia tienen derecho y cuidados y asistencia especiales"15. Por su parte, el artículo 10.2 del Pacto Internacional de Derechos Económicos y Sociales aprobado por Colombia por la Ley 74 de 1968, establece que "se debe conceder especial protección a las madres durante un periodo razonable antes y después del parto"16. Igualmente, el artículo 11 de la Convención sobre Eliminación de todas las Formas de Discriminación contra la Mujer —expedida en Nueva York el 18 de diciembre de 1979 por la Asamblea General d la ONU y aprobada por la Ley 51 de 1981- establece que es obligación de los Estados adoptar "todas las medidas apropiadas para eliminar la discriminación contra la mujer en la esfera del empleo" a fin de asegurarle,

13 Corte Constitucional de Colombia. SENTENCIA C-710 de 1996. (MP Jorge Arango Mejía; mayo 7 de 1996).

14 Código Sustantivo del Trabajo y Código Procesal del Trabajo. 2003. Pág. 493.

15 Declaración Universal de los Derechos Humanos. ONU. 1948.

16 Pacto Internacional de Derechos Económicos y Sociales, Art. 10.2, aprobado por Colombia por la Ley 74 de 1968. 
en condiciones de igualdad con los hombres, "el derecho al trabajo como derecho inalienable de todo ser humano"17.

El Convenio 111 de la OIT "prohíbe la discriminación en materia de empleo y ocupación, entre otros motivos por el de sexo"18. Pero es más; desde principios de siglo, la oıT promulgó regulaciones específicas para amparar a la mujer embarazada. Así, el Convenio N. ${ }^{\circ}$, que entró en vigor el 13 de junio de 1921 y fue aprobado por Colombia por la Ley 129 de 1931, señala en su artículo 3:

En todas las empresas industriales o comerciales, públicas o privadas, o en sus dependencias, con excepción de las empresas en que solo estén empleados los miembros de una misma familia, la mujer: (a) no estará autorizada para trabajar durante un periodo de seis semanas después del parto; (b) tendrá derecho a abandonar el trabajo mediante la presentación de un certificado que declare que el parto sobrevendrá probablemente en un término de seis semanas; (c) recibirá, durante todo el periodo en que permanezca ausente en virtud de los apartados a) y b), prestaciones suficientes para su manutención y las del hijo en buenas condiciones de higiene: dichas prestaciones, cuyo importe exacto será fijado por la autoridad competente en cada país, serán satisfechas por el Tesoro público o se pagarán por un sistema de seguro. La mujer tendrá además derecho a la asistencia gratuita de un médico o de una comadrona ${ }^{19}$.

En vigencia de la Constitución Política de 1991, el constituyente de la época consagra, en el artículo $53^{20}$ del Estatuto Superior, los principios básicos que deben regir las relaciones laborales dentro del Estado social de derecho colombiano, entre las cuales establece que el Congreso expedirá el estatuto del trabajo; además, deja sentado que la ley correspondiente tendrá en cuenta por lo menos los principios mínimos fundamentales de la ley laboral, entre los que destaca la estabilidad en el empleo y la protección especial a la mujer y a la maternidad.

Se cree que fue a partir de la Sentencia C-470 de 1997, con ponencia del Dr. Alejandro Martínez Caballero, que por primera vez en Colombia se abordó el tema del

17 Convención sobre Eliminación de Todas las Formas de Discriminación contra la Mujer. ONU. 1979.

18 Convenio 111 OIT.

19 Convenio N. ${ }^{\circ} 3$ oІт. Junio 13 de 1921. Aprobado por Colombia por la Ley 129 de 1931.

20 Constitución Política de Colombia de 1991, art. 53. 
principio a la estabilidad laboral reforzada, planteada desde la acción de inconstitucionalidad del artículo 239 ordinal 3 del Código Sustantivo del Trabajo, modificado por el artículo 35 de la Ley 50 de 1990. ${ }^{21}$ Los temas planteados fueron: la protección de la mujer embarazada, el fuero sindical y el principio de igualdad, los fundamentos e implicaciones constitucionales de la especial protección de la maternidad en el campo laboral, es decir, el derecho a una estabilidad laboral reforzada, el despido de la mujer embarazada sin autorización previa y la insuficiencia del mecanismo indemnizatorio previsto por la ley y la necesidad de una sentencia integradora. En esta oportunidad, la Corte, al declarar la constitucionalidad de la normatividad acusada concluye que:

16-La única decisión admisible en este caso es integrar en el ordenamiento legal los mandatos constitucionales sobre la igualdad (CP art 13) y la protección a la maternidad en el ámbito laboral (CP arts 43 y 53) 22, de suerte que debe entenderse que carece de todo efecto el despido de una trabajadora durante el embarazo, o en los tres meses posteriores al parto, sin la correspondiente autorización previa del funcionario competente. Esto significa que para que el despido sea eficaz, el patrono debe obtener la previa autorización del funcionario del trabajo, para entonces poder entregar la correspondiente carta de terminación del contrato. Y en caso de que no lo haga, no solo debe pagar la correspondiente indemnización sino que, además, el despido es ineficaz. Esto significa que existe una suerte de omisión relativa del Legislador, puesto que el ordinal acusado no consagró una protección suficiente a la maternidad. Ahora bien, teniendo en cuenta que, conforme a la sentencia C-543 de 1996, la Corte es competente para controlar estas omisiones relativas, es natural que esta Corporación, aplicando el principio de igualdad (CP art. 13), subsane esa omisión tomando en cuenta la regulación de un supuesto análogo, a saber, la regla prevista por el artículo 241 del CST, según la cual esos despidos carecen de toda eficacia ${ }^{23}$.

21 Codigo Sustantivo del Trabajo, art. 239 ordinal 3. Modificado art. 35, Ley 50 de 1990. "Las trabajadoras de que trata el numeral uno (1) de este artículo que sean despedidas sin autorización de las autoridades competentes, tienen derecho al pago de una indemnización equivalente a los salarios de sesenta (60) días, fuera de las indemnizaciones y prestaciones a que hubiere lugar de acuerdo con el contrato de trabajo".

22 Corte Constitucional de Colombia. SENTENCIA C-588 de 1995. (MP Antonio Barrera Carbonell; diciembre 7 de 1995).

23 Corte Constitucional de Colombia. SENTENCIA C-470 de 1997. (MP Alejandro Martínez Caballero; septiembre 25 de 1997). 


\section{La estabilidad laboral para el servidor público}

En relación con los servidores públicos, la Corte precisa que "el artículo 34 de la Ley 50 de 1990 establece un descanso remunerado por razones de parto de doce semanas, y no de ocho como lo señala el artículo 21 del Decreto 3135 de 1968". Ahora bien, la corporación dice que ese artículo de la Ley 50 de 1990 no solo habla en general de toda trabajadora, sin distinguir los ámbitos público y privado, sino que además expresamente señala que esos "beneficios no excluyen al trabajador del sector público", lo cual es lo más conforme al principio de igualdad (CP art. 13). Por tales razones, la Corte concluye que en este punto la Ley 50 de 1991 subrogó parcialmente el artículo 21 del Decreto 3135 de 1968, por lo cual se entiende que el descanso legal remunerado por parto para las servidoras públicas es de doce semanas"24.

El Dr. Eduardo Cifuentes Muñoz, en la Sentencia T-373 del 22 de julio de 1998, estableció que la acción de tutela es un procedimiento preferente y sumario que contiene ciertas garantías mínimas y necesarias para la validez constitucional de un proceso judicial, que no está sometido a la amplitud y al rigorismo de otros debates judiciales que admiten una mayor participación de las partes y un más amplio despliegue de sus derechos procesales; sin embargo, procede como mecanismo transitorio para proteger el derecho a la estabilidad laboral reforzada de la mujer en estado de embarazo ${ }^{25}$.

En la misma sentencia, estableció que los elementos fácticos que deben quedar demostrados para que proceda el amparo transitorio ${ }^{26}$ del derecho a la estabilidad laboral reforzada son los siguientes: "(1) que el despido o la desvinculación se ocasionó durante el embarazo o dentro de los tres meses siguientes al parto; (2) que la desvinculación se produjo sin los requisitos legales pertinentes para cada caso; (3) que el empleador conocía o debía conocer el estado de embarazo de la empleada o trabajadora; (4) que el despido amenaza el mínimo vital ${ }^{27}$ de la actora o que la arbitrariedad resulta evidente y el daño que apareja es devastador"28.

24 Id.

25 Corte Constitucional de Colombia. SENTENCIA T-568 de 1996. (MP Eduardo Cifuentes Muñoz; octubre 28 de 1996); SENTENCIA C-710 de 1996, supra, nota 13.

26 Corte Constitucional de Colombia. SENTENCIA T-141 de 1993. (MP Vladimiro Naranjo Mesa; abril 16 de 1993); SENTENCIA T-497 de 1993. (MP Fabio Morón Díaz; mayo 19 de 1993); SENTENCIA T-119 de 1997. (MP Eduardo Cifuentes Muñoz; marzo 11 de 1997).

27 Corte Constitucional de Colombia. SENTENCIA T-606 de 1995. (MP Fabio Morón Díaz; julio 19 de 1995); SENTENCIA T-311 de 1996. (MP José Gregorio Hernández Galindo; julio 15 de 1996); SENTENCIA T-373 de 1998. (MP Eduardo Cifuentes Muñoz; julio 22 de 1998).

28 Sobre los elementos que deben demostrarse para que proceda la acción de tutela, puede verse el fundamento jurídico n. ${ }^{\circ} 13$ de la Sentencia T-373 de 1998. 
A los directivos sindicales la misma ley laboral les confiere una protección especial, toda vez que prohíbe despedir a un empleado con fuero sindical sin antes haber sido levantado el fuero por un juez, o a cualquier trabajador sindicalizado cuando la empresa se encuentre en etapa de negociación colectiva.

Frente al tema de la estabilidad laboral, desde el derecho comparado se tiene que la Constitución de la República Bolivariana de Venezuela, en sus artículos 87, 88, 89 y 93, consagra el derecho a la estabilidad laboral29; ratifica el derecho a la sindicalización, sin autorización previa, de todos los trabajadores venezolanos, con la finalidad de obtener la mejor defensa de sus derechos e intereses y con libertad de afiliarse o no a ellas. Estas organizaciones no están sujetas a control administrativo por parte del Estado y los trabajadores gozan en virtud de este derecho de una protección especial: la inamovilidad laboral, que tiene por objeto evitar discriminaciones, intromisiones y perjuicios, tendientes a conculcar el libre ejercicio de este derecho, lo cual ya formaba parte de la tradición constitucional venezolana, porque también estaba consagrado en la Constitución de la República de 1961, pero no con el rango de derecho constitucional extensivo a todos los trabajadores.

En el mismo sentido, la hermana República del Ecuador, en el Capítulo IV Sección segunda del trabajo, artículos 35 y 36, establece la estabilidad en el empleo y la incorporación de las mujeres al trabajo remunerado, en igualdad de derechos y oportunidades, garantizándole idéntica remuneración por trabajo de igual valor ${ }^{30}$.

Por su parte, la Constitución Política de la República del Perú, artículos 42-48, establece que "el Estado, reconoce el trabajo como fuente principal de la riqueza, el derecho de estabilidad en el trabajo, advierte que el trabajador solo puede ser despedido por causa justa señalada en la ley debidamente comprobada"31. En el mismo sentido, los artículos 156 y 157 de la Constitución de la hermana República de Bolivia consagran el trabajo como un derecho y un deber constitucional, y ordenan al Estado crear las condiciones que garanticen, para todas las posibilidades laborales, estabilidad en el trabajo y remuneración justa ${ }^{32}$.

También, la Constitución de la República de Chile, en el artículo 19, consagra la libertad de trabajo y su protección. Propicia la libre contratación, al igual que la libre

29 Constitución Política de la República Bolivariana de Venezuela. Disponible en: http:// www.constitución.ve/constitución.pdf

30 Constitución política de la República de Ecuador. Disponible en: http://www.ecuanext. net.ec/ec/constitución/indice.htm>

31 Constitución Política de la República del Perú. Disponible en: http:// www.caipe.org.pe/ rij/bases/legisla/peru/consper.htm

32 Constitución Política de la República de Bolivia. Disponible en: http://www.fndr.gov.bo/ doc normas/CPE.pdf 
elección del trabajo con justa retribución y prohíbe cualquier discriminación que no se base en la capacidad o idoneidad personal".

A través de los diferentes fallos de constitucionalidad y otros en sede de revisión de tutela, la Corte Constitucional de Colombia, en desarrollo del principio y derecho a la igualdad material y el principio de solidaridad (consagrados en el artículo 13 inc. 2-4), amplía la protección del derecho a la estabilidad laboral reforzada a aquellos trabajadores que sufren de alguna discapacidad, o se encuentren en condiciones que los coloque en desventaja frente a otros trabajadores.

El legislador, consciente de la necesidad de avanzar en la protección de este grupo vulnerable, expidió la Ley 361 de 199733, en la que se consagran mecanismos de integración social para personas en condición de discapacidad, incluidas algunas normas de protección laboral. En el inciso segundo del artículo 26 de la referida ley, el legislador estableció la prohibición de dar por terminado el contrato de trabajo a una persona en condición de discapacidad sin la autorización del Ministerio de la Protección Social, en tanto que en el inciso segundo de la misma disposición estableció que el despido llevado a cabo sin tal autorización genera para el empleador la obligación de cancelar una indemnización equivalente a 180 días de trabajo.

Al estudiar la constitucionalidad de la disposición referida, la Corte consideró que "la prohibición establecida en el primer inciso de la disposición referida resultaba incompatible con la permisión del inciso segundo, pues no es posible dotar de efectos jurídicos a una actuación ilegal, o jurídicamente prohibida, a partir del pago de una suma determinada de dinero"34. Posición que compartimos, por cuanto en el primer inciso se protegen los derechos de la mujer respetando los principios y valores constitucionales consagrados en convenios y tratados internacionales, por ello no se admite su desconocimiento abierta vulneración expresada en el inciso segundo.

La Corte decidió integrar en el ordenamiento legal las disposiciones constitucionales relativas al derecho al trabajo, la estabilidad laboral y la eficacia de los

33 Ley 361 del 7 de febrero 1997. Art. 26 inciso 2. "En ningún caso la limitación de una persona podrá ser motivo para obstaculizar una vinculación laboral, a menos que dicha limitación sea claramente demostrada como incompatible e insuperable en el campo que se va a desempeñar. Así mismo, ninguna persona limitada podrá ser despedida o su contrato terminado por razón de su limitación, salvo que medie autorización de la oficina de trabajo. No obstante, quienes fueren despedidos o su contrato terminado por razón de su limitación, sin el cumplimiento del requisito previsto en el inciso anterior, tendrán derecho a una indemnización equivalente a ciento ochenta días del salario, sin perjuicio de las demás prestaciones e indemnizaciones a que hubiere lugar de acuerdo con Código Sustantivo del Trabajo y demás normas que lo modifiquen, adicionen, complementen o aclaren".

34 Corte Constitucional de Colombia. SENTENCIA C-513 de 2000. (MP Álvaro Tafur Gálvis; 25 de mayo de 2004). 
derechos constitucionales, por lo que condicionó la constitucionalidad del inciso segundo del artículo 26 de la Ley 361 de 1996, señalando que este se ajusta a la Constitución, en el entendido de que el despido realizado sin autorización del Ministerio de la Protección Social carece de efectos jurídicos en cualquier caso, por lo que la indemnización establecida en tal disposición tiene un carácter estrictamente sancionatorio.

El principio de estabilidad laboral no equivale a un derecho fundamental a permanecer indefinidamente en un cargo o puesto de trabajo determinado, debido a las limitaciones fácticas y a los intereses legítimos de los empleadores privados y del servicio público, que deben armonizarse con la expectativa de continuidad en las relaciones laborales. Sin embargo, cuando uno de los extremos de la relación laboral está compuesto por un sujeto que se encuentra en un estado de debilidad manifiesta, el derecho a la estabilidad laboral adquiere el carácter de fundamental, en virtud de diversas razones de carácter constitucional, así: (i) la existencia de mandatos de protección especial vinculantes para todos los actores sociales y el Estado; (ii) el principio de solidaridad social y de eficacia de los derechos fundamentales; y (iii) el principio y derecho a la igualdad material, que comporta la adopción de medidas afirmativas en favor de grupos desfavorecidos, o de personas en condición de debilidad manifiesta (art. 13, incisos 2 a 4). Tales normas han llevado a la Corte a considerar que un despido que tiene como motivación —explícita o velada - la condición física del empleado constituye una acción discriminatoria y/o un abuso de la facultad legal de dar por terminado unilateralmente un contrato de trabajo.

La doctrina de la Corte Constitucional ha enunciado de la siguiente forma las reglas y los requisitos para que la acción de tutela proceda para la protección de este derecho y para el reintegro laboral. En principio no existe un derecho fundamental a la estabilidad laboral; sin embargo, para ciertas personas se presenta una estabilidad laboral reforzada en virtud de su especial condición física o laboral, o por encontrarse dentro de grupos poblacionales tradicionalmente marginados o discriminados. Quiere decir que si se ha presentado una desvinculación laboral de una persona que reúna las calidades de especial protección, la tutela no prosperará por la simple presencia de esta característica, sino que será necesario probar la conexidad entre la condición protegida y la desvinculación laboral, constitutiva de un acto discriminatorio y un abuso del derecho.

La tutela puede ser el mecanismo para el reintegro laboral de las personas cuyas circunstancias particulares ameriten la protección laboral reforzada. En todos los casos, es necesario mostrar la afectación de un derecho fundamental como el mínimo vital, la dignidad o el derecho de asociación sindical. El reintegro no tendría 
lugar de presentarse una justa causa para la desvinculación y siempre que esta se hubiera producido con el respeto del debido proceso correspondiente.

En estos casos, para satisfacer esta condición se requiere el permiso previo del despido. De esa forma, con respecto a los trabajadores aforados, la Corte ha sostenido que la acción de tutela procede como mecanismo transitorio para solicitar el reintegro, cuando no se ha surtido el debido proceso para los trabajadores con fuero sindical y el juez laboral de la acción de reintegro ha incurrido en vía de hecho. Esto último sucede, por ejemplo, cuando el juez laboral ante quien se solicita el reintegro se pronuncia sobre la legalidad del despido pues no tiene competencia para ello.

Para el caso de la mujer embarazada, la Corte Constitucional ha tutelado el derecho a la estabilidad reforzada con la finalidad de protegerla contra la discriminación por causa del embarazo. La Corte ha considerado en estos casos que el despido es ineficaz cuando se da durante el embarazo, con previo conocimiento del estado de gravidez por parte del empleador, o durante los tres meses posteriores al parto, sin la debida autorización del funcionario del trabajo. Por consiguiente, dentro del año siguiente al parto procede la tutela como mecanismo transitorio para solicitar el reintegro laboral. En estos casos basta con demostrar, por cualquier medio, que el empleador conocía o debía conocer el estado de embarazo de la mujer y que la decisión afecta su derecho al mínimo vital. En todo caso, se entiende afectado el mínimo vital de la madre cabeza de familia que no tiene otros ingresos.

\section{CONCLUSIONES}

1. La Corte ha encontrado que en la Constitución existen algunos derechos que están implícitos en el ámbito de protección de distintas disposiciones jurídicas iusfundamentales, pero que, sin embargo, no se encuentran textualmente enunciados en ellas. Se trata de los llamados derechos innominados, cuya fuerza vinculante y supremacía jerárquica viene dada por la disposición que los consagra de manera implícita y por los artículos 94 de la Constitución Política y 2 del Decreto 2591 de 1991.

2. La Corte Constitucional ha considerado que existen algunos casos en los que el derecho a la estabilidad en el empleo, consagrado en el artículo 53 de la Constitución Política, merece mayor protección. En estos casos, se ha indicado que existe un derecho constitucional fundamental a la estabilidad laboral reforzada. Este derecho ha sido establecido a favor de los sujetos que gozan de una especial protección constitucional, tales como los 
trabajadores que gozan de fuero sindical y cuya estabilidad laboral resulta fundamental para garantizar el derecho de asociación sindical establecida en el artículo 39 de la carta política; las personas con discapacidades o desaventajadas por encontrarse en situación de debilidad manifiesta y dado el deber de especial cuidado que ordena la Constitución (Art. 54); la mujer embarazada por tratarse de un sujeto tradicionalmente discriminado en materia laboral por su estado de gravidez; y los portadores de VIH/sida.

3. La jurisprudencia ha considerado que en estos casos la indemnización por el despido no constituye un amparo efectivo de los derechos de estos sujetos. En efecto, en el caso en el cual se demuestre que el despido tuvo como causa la pertenencia del empleado al sindicato, su estado de embarazo o su condición de discapacidad, el derecho a la estabilidad laboral reforzada de estos sujetos tendría como consecuencia el derecho al reintegro efectivo. En otras palabras, resulta nulo el despido que tiene origen en un abuso del derecho o en el acto de discriminación que afecta al sindicato, a la mujer embarazada o a la persona enferma o discapacitada.

4. El derecho a la estabilidad laboral reforzada puede ceder ante la existencia de una causa justa para el despido, y siempre y cuando se hubiere respetado el debido proceso laboral. En todos los casos, debe comprobarse el nexo de causalidad entre el despido y la condición protegida (embarazo, disminución física, pertenencia a un sindicato, VIH/sida, madre o padre cabeza de hogar y prepensionados).

\section{REFERENCIAS}

Adalberto Carvajal Salcedo. EduCAdores fRENTE A LA LEY LABORAL. 3. a edición. Rodríguez Quito Editores. (1985).

Antonio Vasquez Vialard. Derecho del trabajo y DE LA SEGURIDAD SOCIAL. Astrea. (1999).

Corte Constitucional de Colombia. Sentencia T-141 de 1993. (mP Vladimiro Naranjo Mesa; abril 16 de 1993).

Corte Constitucional de Colombia. Sentencia T-497 de 1993. (MP Fabio Morón Díaz; mayo 19 de 1993).

Corte Constitucional de Colombia. Sentencia T-606 de 1995. (mP Fabio Morón Díaz; julio 19 de 1995). 
Corte Constitucional de Colombia. SentenCIA C-566 de 1995. (MP Eduardo Cifuentes Muñoz; noviembre 30 de 1995).

Corte Constitucional de Colombia. Sentencia C-588 de 1995. (MP Antonio Barrera Carbonell; diciembre 7 de 1995).

Corte Constitucional de Colombia. Sentencia C-080 de 1996. (mP Fabio Morón Díaz; febrero 29 de 1996).

Corte Constitucional de Colombia. Sentencia C-710 de 1996. (mP Jorge Arango Mejía; mayo 7 de 1996).

Corte Constitucional de Colombia. Sentencia T-311 de 1996. (MP José Gregorio Hernández Galindo; julio 15 de 1996).

Corte Constitucional de Colombia. Sentencia T-568 de 1996. (mP Eduardo Cifuentes Muñoz; octubre 28 de 1996).

Corte Constitucional de Colombia. SentenCIA T-119 de 1997. (mP Eduardo Cifuentes Muñoz; marzo 11 de 1997).

Corte Constitucional de Colombia. Sentencia C-470 de 1997. (mp Alejandro Martínez Caballero; septiembre 25 de 1997).

Corte Constitucional de Colombia. Sentencia SU-747 de 1998. (MP Eduardo Cifuentes Muñoz; diciembre 2 de 1998).

Corte Constitucional de Colombia. SEnTEnCIA T-373 de 1998. (mP Eduardo Cifuentes Muñoz; julio 22 de 1998).

Corte Constitucional de Colombia. SentenCIA C-513 de 2000. (MP Álvaro Tafur Gálvis; 25 de mayo de 2004).

Corte Constitucional de Colombia. Sentencia C-1064 de 2001. (MP Manuel José Cepeda Espinosa y Jaime Córdoba Triviño; octubre 10 de 2001).

Ernst Wolfgang Böckenförde. Estudios sobre Estado DE DERECHO y DEMOCRACIA. Editorial Trotta. (2000).

Guillermo Cabanellas de Torres. Diccionario ENCICLOPÉdico DE DERECHO USUAL. Heliasta. (1979). 
20 El derecho fundamental a la estabilidad laboral reforzada, alcance de la protección constitucional

Guillermo Guerrero Figueroa. COMPENDIO DEL DERECHO LABORAL. Leyer. (1998).

Jairo Villegas Arbeláez. DereCho administrativo LABORAL. TOMO I. Editorial Legis. (1993).

Real Academia Española. DiccionARIO DE LA LENGUA eSPAÑOLA. 23. edición. RAE. (2014). 